\title{
Private nursing homes: contribution to long stay care of the elderly in the Brighton Health District
}

\author{
J BENNETT
}

\begin{abstract}
Two surveys of private nursing homes, designated geriatric wards, and a sample of social service part III homes were carried out in the Brighton Health District using questionnaires supplemented (in the second survey) by some interviews. The dependency of old people in the private nursing homes was more like that of long stay hospital patients rather than that of residents in social services homes. In the private nursing homes, however, a smaller proportion of patients were in the medium to heavy nursing category $(178(31 \%)$ compared with $158(63 \%)$ in the hospital long stay wards) and a larger proportion in the heavy nursing category $(170(30 \%)$ compared with $44(17 \%)$ in the long stay wards). Of the patients in private nursing homes, $401(82 \%)$ were local residents, $488(86 \%)$ were long stay, and $459(88 \%)$ were women; their mean age was 88 years. Two thirds of the patients were over 80 . There were no significant differences between the private nursing homes and the wards in nursing workloads or staffing, except for a slightly higher provision of state registered nurses in the private sector. In the private nursing homes $348(63 \%)$ of the patients had fees paid by private funds, $26(5 \%)$ were in contract beds paid for by the National Health Service, and $176(32 \%)$ were subsidised by the Department of Health and Social Security.

Private nursing homes make a substantial contribution to the care of the elderly in the Brighton Health District, and the health authority should develop a more active partnership with this sector.
\end{abstract}

\section{Introduction}

A remarkable lack of detail is available about patients in private nursing homes, though a substantial proportion are supported by the state. Wade et al studied different care provision for the elderly on a national basis using a stratified sampling technique including eight private nursing homes. ${ }^{1}$ While their report is an important contribution, it is still necessary to examine private nursing homes in the context of a local district, where this may have considerable bearing on the facilities provided by the National Health Service. The aims of this study were to examine the contribution made by private nursing homes to the care of the elderly in the Brighton Health District; to compare characteristics of patients in these establishments with those of patients in geriatric wards and clients in part III accommodation (social services homes); to compare the staffing and style of care in the three types of institutional settings; and in the light of the findings to review the policy and planning issues relating to private nursing homes.

\section{Current provision}

The Brighton Health Authority is responsible for 68600 people aged 65 and over, who constitute $22.9 \%$ of the total population; 33000 are 75 and over. By 2001 there will be 12900 people aged 85 and over compared with

Brighton Health Authority, Brighton General Hospital, Brighton, East Sussex BN2 3EW

J BENNETT, MFCM, DCH, senior registrar in community medicine
7200 at present. There are 345 designated geriatric beds, giving 5.01 beds per 1000 population aged 65 and over, compared with a recent recommendation of $7 \cdot 807 / 1000 .^{2}$ Social services provide 967 places in part III residential homes, giving 14.09 places per 1000 elderly. In 1982 private nursing homes registered to take elderly people had 676 places available, giving $10 \cdot 10$ private beds per 1000 population aged 65 and over in Brighton compared with 5.48/1000 in the South East Thames region and 3.27/1000 nationally. ${ }^{3}$ Figure 1 shows the changes in provision since 1982.

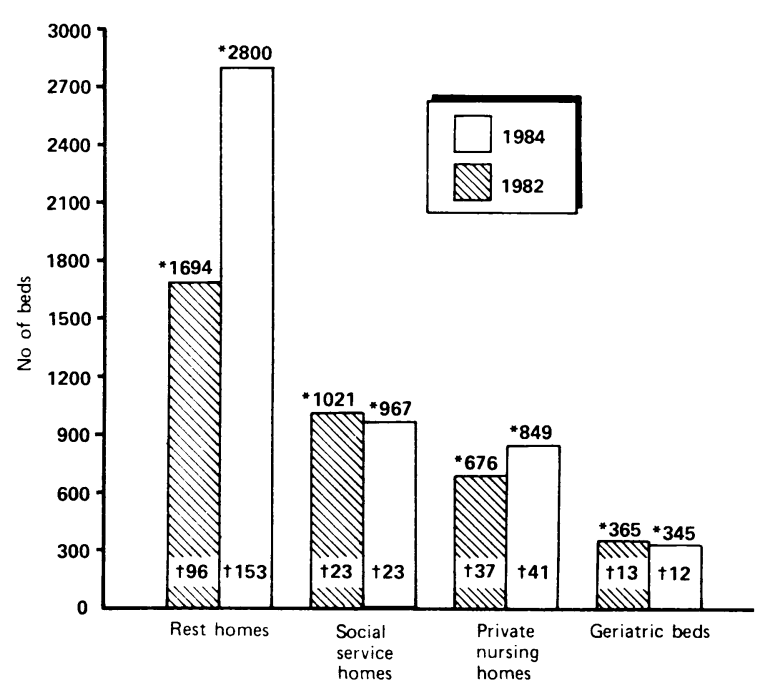

FIG 1-Distribution of various types of institutional accommodation for the elderly in Brighton Health District in 1982 and 1984. (Figures obtained from institutions.)

$\star$ Number of places.

†Number of establishments/wards.

\section{Methods}

The study was carried out in two stages: basic details about the residents (dependency and nursing in private nursing homes) in 1982 and further details about facilities and environment in 1984. Lists of private nursing homes registered in the district were obtained and those classified as "medical and geriatric" and "elderly infirm" approached by telephone and invited to take part (homes for psychogeriatric patients were excluded). A sample of the 23 social services homes in the district was taken ( 10 homes) and a list of all wards (13) designated as having geriatric beds obtained and the persons in charge telephoned and invited to take part. Two specially designed questionnaires were then sent, supplemented with some interviews in the second survey. The questionnaire used to collect the basic census type information in 1982 was based on that devised by Purkiss. ${ }^{4}$

\section{Results}

In the first survey (1982) a $100 \%$ response rate was obtained across all three sectors, from 37 nursing homes covering 565 people, 13 geriatric wards covering 317 people, and 10 social services homes covering 376 people. In the second survey (1984-5) a $90 \%$ response rate was obtained from private nursing homes $(n=35)$ covering 676 people and a $100 \%$ response rate from the 11 geriatric wards covering 260 people and the nine social services homes covering 345 . Four private nursing homes did not return the questionnaire and three homes gave details on facilities but not individual patients' details. Results presented relate to replies received. 


\section{SIZE AND BEDS AVAILABLE}

In 1982 there were 676 beds available in the private nursing homes, which had increased to 812 by 1984 . In 1984 there were four private nursing homes with fewer than 10 places and 15 with $11-19,17$ with $20-37$, and three with more than 40 . The size of the geriatric wards ranged from 19 to 34 beds, nine wards having 24 or more, altogether providing 317 beds. The social services homes had between 23 and 60 places each, five of the 10 homes having 50 places or more. In all they provided 376 places.

\section{DISTRICT OF RESIDENCE}

One hundred and one $(18 \%)$ of the patients in private nursing homes in 1982 were admitted from addresses beyond the Brighton Health District compared with $11(3 \%)$ in social services homes and $13(4 \%)$ in geriatric wards.

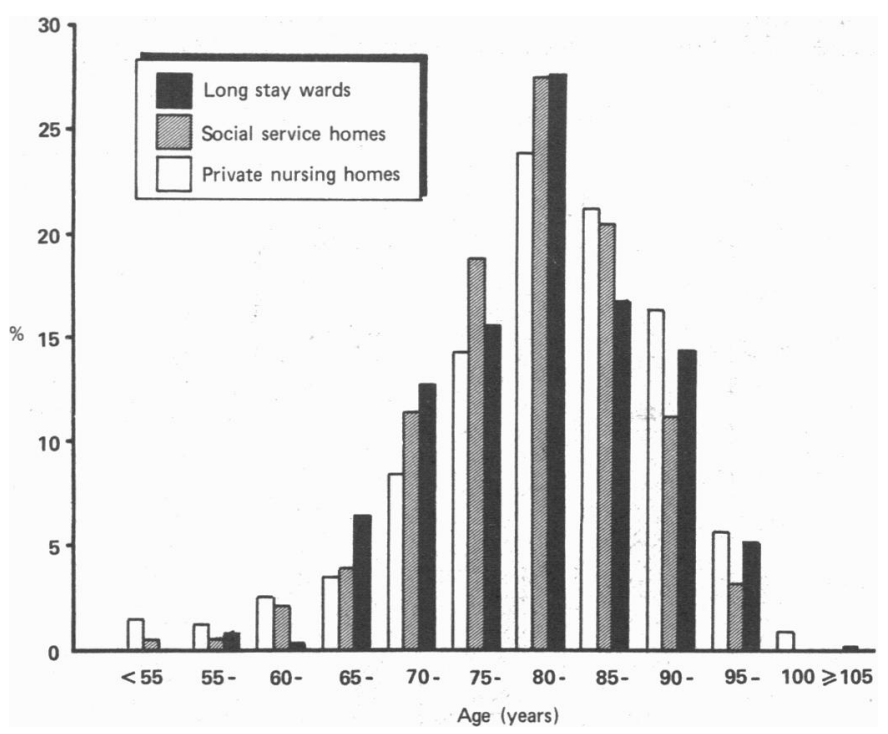

FIG 2-Percentage age distribution of subjects being cared for in three types of institutions in Brighton Health District in 1982.

\section{ADDRESS ON ADMISSION}

Of patients in private nursing homes in 1984, $215(36 \%)$ had been admitted from their own home. A similar proportion $(206 ; 34 \%)$ had been admitted directly from hospital ( 26 were in contract beds). Fifty nine (10\%) had been transferred from another nursing home, $77(13 \%)$ from rest homes, $25(4 \%)$ from a relative's home, $11(2 \%)$ from other or unspecified places, five ( $1 \%)$ from sheltered housing, and only two $(0 \cdot 3 \%)$ had been admitted from social services homes.

The most common routes of admission to a social services home were from the person's own private address $(n=180 ; 53 \%)$, a hospital bed $(70 ; 20 \%)$, and another social services home $(39 ; 11 \%$ - owing to the recent permanent closure of a home and refurbishment of another); 31 clients $(9 \%)$ were admitted from a relative's home, $12(3 \%)$ from sheltered housing, six (2\%) from rest homes, and for three $(1 \%)$ the route was not known.

On the geriatric wards the most common route of admission was from another ward in the hospital ( 133 patients; $51 \%$ ). The second most common route was from the patient's own home $(86 ; 33 \%)$, followed by admission from social services homes $(18 ; 7 \%)$. Only three patients $(1 \%)$ had been admitted directly from private nursing homes to the geriatric wards. Ten (4\%) were admitted from a relative's home, seven (3\%) from a rest home, and three $(1 \%)$ from sheltered housing.

\section{AGE OF- RESIDENTS}

Figure 2 shows the age distribution of the patients and residents in the three types of institution. Over two thirds $(385 ; 68 \%)$ of patients in the private nursing homes were over 80 , as were $234(62 \%)$ in the social services homes and $160(64 \%)$ in long stay wards. Mean ages were $87 \cdot 8$ years in the private nursing homes, 86.5 years in the social services homes, and 89.8 years in the geriatric wards (mean age in rehabilitation wards $87 \cdot 5$ years, long stay wards 90.9 years)

\section{SEX, NUMBER, AND MARITAL STATE OF RESIDENTS}

Table I shows the number and sex distribution of residents in 1982 . 3 Women in care were represented in a ratio of about $4: 1$ in the private nursing homes, 3:1 in social services homes, and 3:1 in geriatric wards; whenc geriatric wards were separated into long stay and rehabilitation wards the preponderance of women in care was most pronounced in the long stay wards $(6: 1)$ and numbers were almost equal on the rehabilitation wards. Marital state was significantly different in the three sectors of care, with a® very low proportion $(14 ; 3 \cdot 7 \%)$ of married people in the social services homes.

TABLE I-Number and sex distribution of residents in three sectors in 1982

\begin{tabular}{lcccccc}
\hline & \multirow{2}{*}{$\begin{array}{c}\text { Private } \\
\text { nursing } \\
\text { homes }\end{array}$} & $\begin{array}{c}\text { Social } \\
\text { services } \\
\text { homes }\end{array}$ & \multicolumn{3}{c}{ Geriatric wards } \\
\cline { 4 - 7 } & Long stay & Rehabilitation & Total \\
\hline No $(\%)$ of men & $106(18 \cdot 8)$ & $91(24 \cdot 2)$ & $37(14 \cdot 8)$ & $33(49 \cdot 3)$ & $71(22 \cdot 4)$ \\
No $(\%)$ of women & $459(81 \cdot 2)$ & $285(75 \cdot 8)$ & $213(85 \cdot 2)$ & $34(50 \cdot 7)$ & $246(77 \cdot 6)$ \\
\hline Total & 565 & 376 & 250 & 67 & 317
\end{tabular}

\section{LENGTH OF STAY}

A greater proportion of patients in the long stay geriatric wards $(143 ; 57 \%) \mathrm{v}$ had been there for less than a year in 1982 compared with patients in private nursing homes $(189 ; 34 \%)$ and residents in social services homes $(118 ; 31 \%)$. Most patients in all sectors $(1543 ; 98 \%)$ had been in care for five years or less. 0 Nine patients $(2 \%)$ in private nursing homes, three $(1 \cdot 2 \%)$ in long stay wards, and $15(3.9 \%)$ in social services homes had been in care for more than ${ }^{+}$ 10 years.

\section{DEPENDENCY}

Dependency of the old people in 1982 was measured using a simple indexo developed by Purkiss. ${ }^{4}$ As expected, low dependency (those who needed no help with "toilet") occurred more frequently in social services homes (1930 patients; $51 \%)$ and in rehabilitation wards $(35 ; 52 \%)$; the figure for private nursing homes was 127 patients $(23 \%)$ and for long stay geriatric wards $20 \overline{0}$ $(8 \%)$ (table II). The two high dependency categories (3 and 4) accounted forő

ABLE II-Dependency categories of patients in private nursing homes and geriatric wards, 1982. Figures are numbers (percentages) of patients

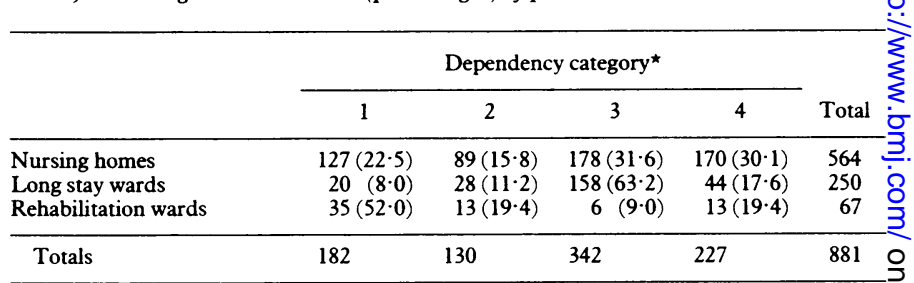

${ }^{\star}$ Category $1=$ least dependent.

$\chi^{2}=129 \cdot 25 ; \mathrm{df}=6 ; \mathrm{p}<0 \cdot 0005$.

202 patients $(80 \%)$ in long stay wards and $348(62 \%)$ in private nursing homes. One hundred and seventy $(30 \%)$ of the high dependency group in private nursing homes, however, were totally dependent (category 4) a compared with $44(18 \%)$ in long stay wards, and the smallest proportion of highly dependent patients $(16 ; 4 \%)$ was noted in the social services homes. This group included those who were bedfast, chairfast, and required complete help with toilet and feeding. Patients in this category were spread evenly throughout the social services homes, showing that each of these $\mathbb{\Phi}$ homes could cope with a few totally dependent residents.

Incontinence-In hospitals in 1984, $191(73 \%)$ of all patients and $159(86 \%) \stackrel{\mathbb{Q}}{\Omega}$ of those in long stay wards were rated as incontinent of urine (sometimes or always or had a catheter) and $160(62 \%)$ as faecally incontinent (sometimes, always, or had a colostomy). In the private nursing homes the proportionso were $345(59 \%)$ and $279(47 \%)$ respectively, and in the social services homes $141(41 \%)$ and $86(25 \%)$. The numbers with indwelling catheters were 750 $(13 \%)$ in the private nursing homes, seven $(2 \%)$ in the social services homes, $?$ 
and $37(17 \%)$ in the long stay wards. In hospital three long stay patients (2\%) had a colostomy, as did two patients $(0.5 \%)$ in social services homes and nine $(2 \%)$ in private nursing homes.

Confusion-The number of confused (sometimes or always) patients in social services homes $(140 ; 41 \%)$ was substantial but was greater in the private nursing homes $(334 ; 56 \%)$. A minority of matrons of private nursing homes stated that they found it difficult to cope with wandering or confused patients, and four homes stated that they would not accept such patients. In all the wards 151 patients $(58 \%)$ were rated as sometimes or always confused, with a difference between rehabilitation wards (20 patients; $27 \%$ ) and long stay wards $(131 ; 71 \%)$.

\section{PRIMARY CARE AND MEDICATION}

Contrary to what was expected, only 65 patients $(11 \%)$ in the private nursing homes in 1984 had a private general practitioner. For 390 patients $(72 \%)$ in private nursing homes their present general practitioner was the one they had had before admission. In the social services homes 225 residents $(65 \%)$ had their original general practitioner.

Data on medication were available for 557 patients $(88 \%)$ in private nursing homes, 331 residents ( $96 \%)$ of social services homes, and $221(85 \%)$ ward patients. Only a small proportion of patients were not receiving any medication. Psychotropic drugs, analgesics, diuretics, and laxatives were the most common drugs being used (table III).

TABLE III-Estimated numbers and percentages of patients receiving certain categories of medication

\begin{tabular}{|c|c|c|c|}
\hline Medication & $\begin{array}{c}\text { Private } \\
\text { nursing } \\
\text { homes } \\
(n=557)\end{array}$ & $\begin{array}{c}\text { Social } \\
\text { services } \\
\text { homes } \\
(\mathbf{n}=331)\end{array}$ & $\begin{array}{c}\text { Geriatric } \\
\text { wards } \\
(\mathrm{n}=221)\end{array}$ \\
\hline \multirow{2}{*}{\multicolumn{4}{|c|}{ Psychotropic drugs: }} \\
\hline & & & \\
\hline $\begin{array}{l}\text { Minor tranquillisers-for example, diazepam } \\
\text { Major tranquillisers-for example, }\end{array}$ & $66(12)$ & $13(4)$ & $26(12)$ \\
\hline chlorpromazine & $76(14)$ & $51(15)$ & $41(19)$ \\
\hline Hypnotics-for example, nitrazepam & $180(32)$ & $91(27)$ & $46(21)$ \\
\hline $\begin{array}{l}\text { Antidepressants; tricyclics-for example, } \\
\text { amitriptyline }\end{array}$ & $41 \quad(7)$ & $18(5)$ & $14(6)$ \\
\hline $\begin{array}{l}\text { Monoamine oxidase inhibitors - for example, } \\
\text { phenelzine }\end{array}$ & $4(0 \cdot 7)$ & $2(0 \cdot 6)$ & $11(5)$ \\
\hline $\begin{array}{l}\text { Other antidepressants—for example, lithium, } \\
\text { trazodone }\end{array}$ & $9(2)$ & 9 (3) & $16(7)$ \\
\hline \multicolumn{4}{|l|}{ Analgesics: } \\
\hline Paracetamol/dextropropoxyphene & $129(23)$ & $45(14)$ & $56(25)$ \\
\hline Codeine/morphine & $18(3)$ & $14(4)$ & $15(7)$ \\
\hline Antiarthritic-for example, ibuprofen & $39(7)$ & $22(7)$ & $18(8)$ \\
\hline \multicolumn{4}{|l|}{ Other specified categories: } \\
\hline Antiparkinsonian drugs (excluding Kemadrin) & $38(7)$ & $23(7)$ & $24(11)$ \\
\hline Insulin and other hypoglycaemic drugs & $21(4)$ & $21(6)$ & $11(5)$ \\
\hline Cardiac regulators & $108(19)$ & 38 (11) & 32 (15) \\
\hline Diuretics & $205(37)$ & $97(29)$ & $37(17)$ \\
\hline Hypotensives & $30(5)$ & $20(6)$ & $7(3)$ \\
\hline Laxatives & $139(25)$ & $28(9)$ & $65(29)$ \\
\hline \multicolumn{4}{|l|}{ Other unspecified drugs: } \\
\hline All other & $137(25)$ & $96(29)$ & $78(35)$ \\
\hline Anticonvulsants & $15(3)$ & $18(5)$ & $24(11)$ \\
\hline Hormones & $41(7)$ & $15(5)$ & $14(6)$ \\
\hline Antibiotics & $22(4)$ & $12(4)$ & $5(2)$ \\
\hline
\end{tabular}

\section{NURSING, STAFFING, AND WORKLOADS}

Nursing time in the 11 largest private nursing homes (20-37 residents) in 1982 was compared with that in the nine exclusively long stay wards (with 19-35 patients). In the long stay wards a total of 26.25 whole time equivalent state registered nurses were looking after 211 patients (145 dependency category 3,35 dependency category 4 ). In the private nursing homes a total of 54.85 whole time equivalent state registered nurses were looking after 283 patients (75 category 3, 101 category 4 ). The ratios of whole time equivalent state registered nurses to patients (including those in categories 3 and 4 ) were therefore $19 \cdot 4: 100$ in the private nursing homes and $12 \cdot 4: 100$ in the long stay wards.

Nursing workloads were calculated using the ratio $2: 3: 4: 7$ devised by Norwich and Senior, ${ }^{56}$ relating to dependency levels $1,2,3$, and 4 . A comparison of total nursing workload, individual staff workload, and ratio of staff to residents showed no significant difference in the long stay wards and the 11 largest nursing homes. The only significant difference found was in the slightly higher provision of state registered nurses in the private sector.

Respondents were asked if any of their nurses had received training in geriatric nursing; $27(77 \%)$ replied. In $16(59 \%)$ of the private nursing homes it was stated that some nurses had received training in geriatrics.

Agency staff were used by eight $(89 \%)$ of the social services homes, nine $(82 \%)$ of the geriatric wards, and $23(74 \%)$ of the private nursing homes (no reply from one).

\section{PARAMEDICAL SERVICES}

Table IV shows the proportions of patients in 1984 receiving paramedical services. No distinction was made on the questionnaire between diversional therapy and more formal occupational therapy. The long stay wards varied widely in the pattern of services available to their patients. Four (36\%) stated that there was never any physiotherapy carried out in the wards and three others that it was available only when requested. In many respects the paramedical services in the long stay wards were similar in quantity to those in the private nursing homes.

Chiropody services used by the private nursing homes were almost exclusively provided privately, $263(93 \%)$ of the patients (where information was available) receiving the service privately and $21(7 \%)$ receiving it on the NHS (table V).

TABLE IV-Details of paramedical services received by patients in the three sectors. Figures are numbers (percentages) of patients

\begin{tabular}{lcccc}
\hline & $\begin{array}{c}\text { Private } \\
\text { nursing homes } \\
(\mathrm{n}=604)\end{array}$ & $\begin{array}{c}\text { Social services } \\
\text { homes } \\
(\mathrm{n}=340)\end{array}$ & $\begin{array}{c}\text { Long stay } \\
\text { wards } \\
(\mathrm{n}=185)\end{array}$ & $\begin{array}{c}\text { Rehabilitation } \\
\text { wards } \\
(\mathrm{n}=75)\end{array}$ \\
\hline $\begin{array}{l}\text { Occupational therapy } \\
\begin{array}{l}\text { Physiotherapy } \\
\text { Chiropody }\end{array}\end{array}$ & $42(7)$ & $27(8)$ & $131(71)$ & $66(88)$ \\
& $66(11)$ & $2(0 \cdot 6)$ & $30(16)$ & $66(88)$ \\
\hline
\end{tabular}

TABLE V-Analysis of whether services received by patients in private nursing homes were inclusive in total nursing home fee or not. Figures are numbers (percentages) of establishments

\begin{tabular}{|c|c|c|c|c|}
\hline & No & $\begin{array}{l}\text { Included } \\
\text { in fee }\end{array}$ & $\begin{array}{l}\text { Not included } \\
\text { in fee }\end{array}$ & $\begin{array}{c}\text { Not } \\
\text { provided }\end{array}$ \\
\hline $\begin{array}{l}\text { Occupational therapy } \\
\text { Physiotherapy } \\
\text { Chiropody }\end{array}$ & $\begin{array}{l}33 \\
34 \\
35\end{array}$ & $\begin{array}{l}8(24) \\
3(9) \\
4(11)\end{array}$ & $\begin{array}{l}16(48) \\
22(65) \\
26(74)\end{array}$ & $\begin{array}{l}9(27) \\
9(26) \\
5(14)\end{array}$ \\
\hline
\end{tabular}

\section{PHYSICAL ENVIRONMENT}

In 1984 the social services homes provided the most privacy in terms of the proportion of single rooms available $(236(78 \%)$ of total rooms); private nursing homes provided 344 single rooms $(67 \%$ of the total $)$ and the geriatric wards only seven side rooms (one single room and six double rooms) for 250 long stay patients.

Social services homes included the highest proportion $(8 ; 89 \%)$ with a day room available. All had dining rooms and most had more than one day room. About half of the private nursing homes had a day room and nine $(81 \%)$ of the geriatric wards had a day room. Provision of a separate dining room and day room is recommended for private nursing homes, but is not obligatory; only $10(29 \%)$ had a separate dining room.

\section{FINANCE}

Information on the exact fee paid in 1984 by each resident was available from 23 homes covering 401 patients. Information on Department of Health and Social Security subsidies was available from 31 homes (some aggregated data). Fees ranged from $£ 110$ to $£ 350$ a week (late 1984 , early 1985). Seventy eight patients $(19 \%)$ were paying more than $£ 200$ a week. The range of fees bore no particular relation to the size of the home. The DHSS standard payment at the time of the survey was $£ 164$ and the most common fee paid (for shared or single rooms) was between $£ 160$ and $£ 179$ a week. Ten homes had no patients receiving a DHSS subsidy, 12 homes had more than half receiving it, and three of these homes had more than three quarters of their residents receiving this subsidy. In general at the time of the survey attendance allowance was used to top up the fees, and in 23 homes for which 
information was available 254 patients (68\%) were receiving this. In three homes all residents were receiving the attendance allowance and in 10 homes $\mathbf{9 0 \%}$ were receiving it. One patient was funded by Private Patients' Plan and eight by the British United Provident Association. For 31 private nursing homes $348(63 \%)$ of the weekly fees were paid by private funds, $26(5 \%)$ were for contract beds and paid by the NHS, and $176(32 \%)$ were paid by the DHSS.

In the social services homes the statutory minimum fee paid by a resident was $£ 28.65$ a week (early January 1985), usually paid out of the pension. For residents with more than $£ 1200$ capital 25 p a week for every complete $£ 50$ over the $£ 1200$ limit was contributed; the proportion of residents contributing in this way ranged from $53 \%$ to $83 \%$ within each home, and in only three of the homes were fewer than $70 \%$ of residents contributing.

\section{Discussion and recommendations}

The results of this study have for the first time enabled the characteristics of elderly people in private nursing homes and the facilities provided in the Brighton Health District to be clarified and compared with those in hospitals and social services homes.

The main limitation of this study is that the exact contribution by the private sector in providing institutional care for the elderly has not been fully established, as the private and voluntary residential homes registered with the social services and private and statutory sheltered housing were not included. Rest homes now offer over twice the number of places that social services provide (fig 1), and the number of private sheltered housing planning applications is roughly five times that of local authority applications.

\section{THEORETICAL REOUIREMENT FOR GERIATRIC BEDS IN DISTRICT}

In 1982, 170 people in the highest dependency category (bedfast or chairfast, needing complete help with "toilet" and feeding) were receiving care in private nursing homes, and 16 in this category were in social services homes. When these were added to the available designated geriatric beds in this district the "equivalent" number was still about 100 short of the need assessed by the DHSS (according to normative planning) in this district.

Alternative styles of care should be explored, such as having more nursing input into social services homes with the possibility of joint control of a certain number of places in these homes. Godber has argued for closer collaboration between part III and long stay hospital sectors with a radical shift in the way the clientele are split. He points out that if social service departments had access to some of the funds currently soaked up by the private sector they could enlarge the scope of the social services homes towards the nursing home model.

It is imperative for district health authority officers to take a keen interest in developing and fostering cooperation with the private sector in order to achieve the mutual goal of good patient care and to obtain early warning about closures. ${ }^{48}$

A nursing home representative should be invited to take part in planning the district's services for elderly people, and there should be regular meetings between staff of the health authority and the heads of the homes. Access to NHS services should be clear and proprietors should be informed of those services they can reasonably expect. Many owners would welcome cooperation with the NHS in order to provide remedial facilities.

The possibility of extending the facility of NHS in service training departments to untrained staff in the nursing home sector-for example, in teaching basic nursing skills-has been suggested by Young ${ }^{9}$ and Day and Larder. ${ }^{10}$ This would help to increase the cooperation between the private sector and the NHS and raise the standard of training in the private sector. The possibility of a clinical nurse manager or education staff from the school of nursing arranging teaching in private nursing homes by invitation should be investigated, and also informal visits to geriatric wards by private nursing home owners might be arranged.

Discharge of hospital patients to private nursing homes is a setting where improvement of present arrangements might be achieved by requiring that before discharge hospital staff, com- munity liaison staff, a clinical nurse manager with responsibility for inspecting private nursing homes, and other relevant people meet along the lines of a case conference, such as is normal practice before admission to a social services home. A hospital discharge form for use in those cases where the elderly person is being discharged to a private nursing home has been devised. The matrons of the accepting homes are being encouraged to come to the ward to discuss the future care of the patient with ward staff.

Effective arrangements for exchange of information should be made, such as an administrator from the community unit sending DHSS hazard notices and other relevant health circulars routinely to private nursing homes. Other material such as articles on care of the elderly and notices of seminars, lectures, and so on should also be sent to homes. Extra lines of communication might encourage a continuing and constructive dialogue with home owners and a move away from the more traditional role of registration and inspection only.

Acknowledgment is due to Professor M D Warren for commenting on drafts of this paper and to him and Professor S L Morrison; Dr G Williams Mrs R Brown, of Guy's Hospital Medical School; and Miss C Leavy and Mr R Discombe, of University of Sussex Computing Centre, for help with the surveys; Dr A Clark, Dr G Mankikar, and Miss M Sharp; and Mr T Kabisa and $\mathrm{Mr}$ C Burgon, of East Sussex County Council Social Services Department, for allowing their patients to be studied. Thanks are also due to $\mathrm{Mr} \mathrm{D}$ Bowring and Mrs E Cook, NHS nursing home inspection staff, and all the matrons, sisters, and administrators in individual institutions who contributed to the collection of the information, particularly Mrs C M Galletly and $\mathrm{Mr}$ W Dawson, Registered Nursing Homes Association, without whose cooperation this project could not have been carried out. I am also grateful to Miss $\mathrm{H}$ Glockling and Mr P Douglas for help with word processing during the preparation of the manuscript.

A complete report of the study was accepted by the Faculty of Community Medicine for the part II membership.

\section{References}

1 Wade B, Sawyer L, Bell J. Dependency with dignity: different care provision for the elderly. London Bedford Square Press, 1983.

2 South East Thames Regional Health Authority. Geriatric bed norms, a consultative document. East Croydon: SETRHA, 1983.

3 Registered Nursing Homes Association. Reference book. London: Registered Nursing Homes Association, 1981, 1982-3.

4 Purkiss $M$. Long stay care of the elderly in a health district with special reference to nursing Purkiss M. Long stay care of the elderly in a health district with special reference to nursing
homes. London: Faculty of Community Medicine, 1982. (Thesis submitted for MFCM part II.) homes. London: Faculty of Community Medicine, 1982. (Thesis submitted for MFCM part II.)
Norwich HS, Senior DE. Determining nursing establishments. Nursing Times 1971;67:17-20.

5 Norwich HS, Senior DE. Determining nursing establishments. Nursing Times 1971;67:17-20. North East Thames Regional Health Authority. Draft repori hospitals. London: NETRHA, 1978. (Report No 821.)

7 Godber C. Private rest homes: answers needed. Br Med J 1984;288:1473-4.

8 Andrews K. Private rest homes in the care of the elderly. Br Med f 1984;288:1518-20.

9 Young J. The case for small nursing units. In: Shegog RFA, ed. The impending crisis of old age. London: Oxford University Press, 1981.

10 Day P, Larder D. Nursing manpower in privute and voluntary nursing homes for the elderly. Bath: University of Bath, 1986. (Bath Social Policy Papers, series No 8.)

(Accepted 8 fuly 1986)

In our practice we have recently seen a few patients with mild, self limiting, upper respiratery tract infections associated with pronounced hypertrophy of the papillae of the tongue giving a strawberry tongue appearance that is less aggressive and localised than that associated with a streptococcal infection. What is this syndrome?

A "strawberry tongue" is not seen only in scarlet fever. Any condition affecting the mucus membrane of the tongue resulting in peeling of surface layers can give this appearance including, for example, measles, toxic shock, and Kawasaki disease. Several respiratory viruses and enteroviruses, which produce upper respiratory tract symptoms, are protean in their manifestations and could have been responsible for the syndrome described. Modern virological techniques are allowing the re-evaluation of many "classic" signs and symptoms, and culture. Immunofluorescence and serological techniques are increasingly available to general practitioners. If an unusual outbreak can be ascribed to a particular organism it should be reported to PHLS Communicable Disease Surveillance Centre (England, Wales, and Northern Ireland) or Communicable Diseases (Scotland) Unit.-ERIC WALKER, lecturer in infectious diseases, Glasgow. 